\title{
Spirituality, moral injury and mental health among Chinese health professionals
}

\author{
Zhizhong Wang, Faten Al Zaben, Harold G. Koenig and Yuanlin Ding
}

\section{Background}

Moral injury has been found to be prevalent among healthcare professionals during the COVID-19 public health crisis.

\section{Aims}

The present study examines the relationship between spirituality, moral injury, and mental health among physicians and nurses in mainland China during the COVID-19 pandemic.

\section{Method}

An online cross-sectional study was conducted involving 3006 physicians and nurses in mainland China, where the COVID-19 pandemic has caused high rates of hospital admission and death. The Moral Injury Symptoms Scale-Health Professional was administered, along with measures of mental health and spirituality. Hierarchical linear regression modelling was used to examine the mediating and moderating role of moral injury in the relationship between spirituality and mental health.

\section{Results}

Spirituality was positively correlated with moral injury ( $\beta=2.41$, $P<0.01)$, depressive symptoms $(\beta=0.74, P<0.01)$ and anxiety symptoms ( $\beta=0.65, P<0.01)$ after controlling sociodemographic variables. Moral injury significantly mediated the relationship between spirituality and both depression and anxiety, explaining $60 \%(0.46 / 0.76)$ of the total association between spirituality and depression and $58 \%(0.38 / 0.65)$ of the association with anxiety. No moderating effect of moral injury was found on the spirituality-mental health relationship.

\section{Conclusions}

Although they were the findings of a cross-sectional study, these results suggest that concern over transgressing moral values during the pandemic may have been a driving factor for negative mental health symptoms among chinese health professionals for whom spirituality was somewhat important. Future longitudinal studies are needed to determine the causal nature of these relationships.

\section{Keywords}

Moral injury; depression; healthcare professional; mediation; COVID-19; spirituality.

\section{Copyright and usage}

(c) The Author(s), 2021. Published by Cambridge University Press on behalf of the Royal College of Psychiatrists. This is an Open Access article, distributed under the terms of the creative commons Attribution licence (http://creativecommons.org/ licenses/by/4.0/), which permits unrestricted re-use, distribution, and reproduction in any medium, provided the original work is properly cited.

\section{Moral injury and mental health}

Moral injury among first-line healthcare workers during the COVID-19 pandemic has received considerable attention during the past year. ${ }^{1,2}$ Litz et al defined moral injury as 'perpetrating, failing to prevent, bearing witness to, or learning about acts that transgress deeply held moral beliefs'. ${ }^{3}$ Moral injury is thought to be a common experience characterised by negative responses such as shame, guilt, self-condemnation, feelings of betrayal, difficulty trusting and difficulty forgiving. ${ }^{4}$ Previous studies of war veterans have found that moral injury consistently coexists with suicide, depression, post-traumatic stress disorder (PTSD) and substance use disorders. ${ }^{5-7}$ Those who suffer from potentially morally injurious events, such as killing or wounding others, engaging in retribution or disproportionate violence, may have psychological injuries and injuries to their spiritual health and well-being (i.e. the sense of peace and fulfilment in life, and feeling that life has purpose and meaning).

\section{Healthcare professionals face risk of moral injury}

Although the concept of moral injury originally arose in military settings among those suffering from wartime trauma acquired during combat, moral injury may also occur among healthcare professionals, particularly when clinicians feel their ability to deliver care is compromised by the systems being implemented by hospitals, clinics and other organisations (e.g. insurance, reimbursement, electronic health records). ${ }^{8,9}$ Physicians and nurses can be exposed to potentially morally injurious events in which they face ethical dilemmas related to agonising life-death decisions. Physicians have often been asked to decide between life and death by allocating life-saving medical resources between patients in hospitals where medical devices (ventilators), personal protective equipment and lifesaving medications are in short supply, particularly during the COVID-19 pandemic. This may be associated with a sense of helplessness, shame and guilt when hundreds of patients under their care die each day and nothing can be done to save them. ${ }^{10}$ Owing to a recent increase in patient-physician mistrust and violence against physicians, ${ }^{11}$ moral injury may also be a consequence of the violence that physicians experience due to perceived betrayal by the patients they serve. In China, violence against healthcare workers has been recognised as a public health concern owing to the possible triggering factors, which include patients experiencing long waits for short appointments, suspicions that expensive investigations or medications might benefit the doctor or hospital more than themselves, media revelations of poor practice and of questionable relationships between some doctors and industry, and limited means of recourse for dissatisfaction. ${ }^{12}$ Many physicians have been killed or injured during the past decade owing to such violence, beginning even before COVID-19. ${ }^{13}$ At least one qualitative study has suggested that the term 'moral injury' is useful for exploring medical students' experience when participating in their emergency medicine rotations. ${ }^{14}$

\section{Spirituality, moral injury and mental health}

Spirituality is an awareness of the metaphysical, the religious, and has to do with sources of meaning and purpose in life. In practice, spirituality includes but is not limited to participation in organised religion, meditation, prayer, contemplative reflection and activities fostering self-growth, meaning, purpose, and connections with 
others and with nature. ${ }^{15}$ Moral injury is often associated with spiritual suffering and a need to find hope, trust, reconnection, reconciliation and wholeness. ${ }^{16}$ Spiritual beliefs may provide coping resources (cognitive, social) and rituals (confession, repentance) for dealing with moral transgressions. Studies have found that spirituality is inversely associated with moral injury in US veterans ${ }^{17}$ and US healthcare professionals, ${ }^{18}$ and it may help to moderate the effects of moral injury on PTSD symptoms or promote recovery when such difficulties emerge. ${ }^{19}$ Spiritual beliefs, however, may also contribute to self-condemnation for failure to live up to the high moral standards advocated by religious bodies, thereby contributing to moral injuries. ${ }^{20}$ Several interventions have been developed to address moral injury in the context of PTSD,${ }^{21}$ including a spiritually-integrated version of cognitive processing therapy that targets moral injury among veterans and active-duty military with PTSD symptoms. $^{22,23}$

To our knowledge, no research has yet examined the relationship between spirituality and moral injury among physicians and nurses in mainland China. The present study seeks to explore the associations among spirituality, moral injury and mental health in a national sample of largely secular Chinese healthcare professionals using an online survey. We hypothesised that: (a) spirituality would be positively associated with moral injury scores; (b) spirituality would be positively related to depressive and anxiety symptoms in this secular sample; and (c) moral injury would help to explain (mediate) the relationship between spirituality and depressive/anxiety symptoms.

\section{Method}

\section{Participants and procedure}

Complete details on enrolment of participants have been described elsewhere. ${ }^{24}$ In brief, a total of 4003 healthcare professionals were recruited from mainland China using a snowball sampling technique. An online survey was conducted between 27 March and 26 April 2020, about 1 month after the COVID-19 pandemic reached its peak in mainland China. Of those approached, 3975 participants agreed to complete the survey; of them, 968 were excluded owing to having been in practice for less than 2 years, having two or more items missing on study measures, or giving the same or similar answer across all items (indicating a lack of thoughtfulness when responding to the questions). As a result, 3006 participants were included in the final analysis.

Inclusion criteria were (a) being a physician or nurse and (b) length of time in practice at least 2 years. Exclusion criteria were (1) history of 6 months or more during the past 2 years of an extended break from practice for any reason; (2) inability to use the internet or other mobile device owing to vision or other physical health problem preventing the completion of an online questionnaire; and (3) not formally licensed to practice medicine or nursing in China.

\section{Ethics statement}

All procedures contributing to this work complied with the ethical standards of national and institutional committees on human experimentation and with the Helsinki Declaration of 1975, as revised in 2008. All procedures involving human subjects were approved by the institutional review board of Ningxia Medical University (protocol \#2020-112).

\section{Consent statement}

The survey was designed as anonymous, and participants had to provide online consent before proceeding.

\section{Measures}

Information on sociodemographic characteristics was collected, including age, gender, marital status, education, ethnicity (Chinese Han or minorities), specialty, work area, and length in practice.

Moral injury was assessed using the 10-item Moral Injury Symptom Scale-Health Professional (MISS-HP) developed by Mantri and colleagues (2020). ${ }^{25}$ This measure assesses ten dimensions of moral injury: betrayal, guilt, shame, moral concerns, loss of trust, loss of meaning, difficulty forgiving, self-condemnation, spiritual struggle and loss of faith. Response options for each of the ten items range from 1 to 10 , indicating agreement or disagreement, resulting in a total score that ranges from 10 to 100 , with higher scores indicating greater moral injury. ${ }^{26}$ The MISS-HP was translated into Chinese following a standard procedure. ${ }^{27}$ Cronbach's alphas in the present sample were 0.71 in nurses and 0.70 in physicians.

The assessment of mental health included measures of depressive and anxiety symptoms using the nine-item Patient Health Questionnaire (PHQ-9) for depression and the seven-item Generalized Anxiety Disorder (GAD-7) scale. Both PHQ-9 and GAD-7 are rated on a four-point Likert scale from 0 (not at all) to 3 (nearly every day). ${ }^{28,29}$ Higher scores indicate more severe symptoms of depression or anxiety. Chinese versions of the PHQ-9 and GAD-7 have been shown to have acceptable internal and testretest reliability as well as construct and factor analytic validity in medical and general population settings. ${ }^{30,31}$ Cronbach's alphas in the present sample were 0.91 for the PHQ- 9 and 0.94 for the GAD-7.

Spirituality was assessed using a visual analogue scale from 0 (not at all important) to 100 (very important) after asking the question: 'In general, how important are spiritual beliefs in your daily life?' This question is commonly used to assess spirituality in secular societies and has been strongly associated with psychological well-being. ${ }^{32}$

Religious affiliation was also determined by asking the question: 'What is your religion?' Religious affiliation was categorised for analysis into four groups: $1=$ none, $2=$ Chinese religion (Buddhist, Daoist, etc.), $3=$ Western religion (e.g., Christian), and $4=$ Muslim.

\section{Statistical analyses}

Descriptive statistics were used to determine average scores with s.d. values and ranges for continuous variables and numbers and percentages for categorical variables. Bivariate analyses were conducted using Pearson's $r$ for continuous variables and student's $t$-test or analysis of variance for comparisons of continuous variable scores across categorical variable responses.

Hierarchical linear regression modelling was used to examine the mediating effect of moral injury in the relationship between spirituality and mental health (depression and anxiety), controlling for demographic variables. First, associations between spirituality and mental health (depression and anxiety separately) were determined after controlling for demographic variables (model 1); this was followed by adding moral injury to the model (model 2). Finally, an interaction term between moral injury and spirituality was added to model 2 to determine whether moral injury moderated the relationship between spirituality and mental health states (model 3).

Bootstrap methods of the PROCESS procedure in SPSS designed by Hayes ${ }^{33}$ were employed to examine the mediating effect of moral injury in the relationship between spirituality and depression/anxiety. The IBM SPSS 23.0 version was used to perform all analyses. The alpha level was set to 0.05 for statistical significance.

\section{Results}

As indicated in Table 1, the final sample consisted of 583 nurses and 2423 physicians. Participants were $65 \%$ female, $12.3 \%$ were minorities, nearly two-thirds (62.5\%) provided in-patient care, and most 


\begin{tabular}{|c|c|c|c|c|}
\hline Variable & $N(\%)$ & Mean (s.d.) & MISS-HP, ${ }^{a}$ mean (s.d.) & $B(95 \% \mathrm{Cl})^{\mathrm{b}}$ \\
\hline \multicolumn{5}{|l|}{ Gender } \\
\hline Female & $1957(65.1)$ & & $46.7(12.4)$ & \multirow{2}{*}{$0.72(-0.27,1.72)$} \\
\hline Male & $1049(34.9)$ & & $47.4(13.2)$ & \\
\hline \multicolumn{5}{|l|}{ Marital status } \\
\hline Unmarried & $656(21.8)$ & & $48.4(12.1)^{\star \star}$ & \multirow{3}{*}{$-0.67(-1.80,0.46)$} \\
\hline Married & $2266(75.4)$ & & $46.5(12.8)$ & \\
\hline Divorced/widowed & $84(2.8)$ & & $46.3(12.3)$ & \\
\hline \multicolumn{5}{|l|}{ Ethnicity } \\
\hline Han & 2637 (87.7) & & $46.9(12.7)$ & \multirow[t]{2}{*}{$-0.10(-1.48,1.27)$} \\
\hline Minorities & $371(12.3)$ & & $46.9(12.1)$ & \\
\hline \multicolumn{5}{|l|}{ Nurse/physician } \\
\hline Nurse & $583(19.4)$ & & $46.2(12.2)$ & \multirow[t]{2}{*}{$0.91(-0.37,2.18)$} \\
\hline Physician & $2423(80.6)$ & & $47.1(12.8)$ & \\
\hline \multicolumn{5}{|l|}{ Work area } \\
\hline In-patient & $1878(62.5)$ & & $46.9(12.8)$ & \multirow{4}{*}{$-0.21(-0.75,0.32)$} \\
\hline Out-patient & $714(23.8)$ & & $47.0(12.6)$ & \\
\hline ICU/emergency & $280(9.3)$ & & $46.8(12.6)$ & \\
\hline Other & $134(4.5)$ & & $48.1(10.8)$ & \\
\hline \multicolumn{5}{|l|}{ Education } \\
\hline Bachelor & $2029(67.5)$ & & $47.1(12.5)$ & \multirow[t]{3}{*}{$0.44(-0.33,1.22)$} \\
\hline Master & $813(27.0)$ & & $46.8(13.0)$ & \\
\hline Ph.D. & $164(5.5)$ & & $45.8(13.2)$ & \\
\hline Age (range $=20-70$ ), years & & $35.4(8.1)$ & $-0.082^{\star \star}$ & $-0.12(-0.19,-0.06)^{\star *}$ \\
\hline LOP (range $=2-50$ ), years & & $11.6(8.5)$ & $-0.085^{\star *}$ & $-0.11(-0.17,-0.05)^{\star *}$ \\
\hline \multicolumn{5}{|l|}{ Religious affiliation } \\
\hline No & 2680 (89.2) & & $46.8(12.7)$ & \multirow[t]{4}{*}{$0.42(0.25,-0.30)$} \\
\hline Christian/Catholic & $29(1.0)$ & & 47.7 (11.2) & \\
\hline Buddhist/Taoist & $103(3.4)$ & & 48.6 (13.5) & \\
\hline Islam & $194(6.5)$ & & $47.5(11.7)$ & \\
\hline Depression (range = 0-30) & & $10.6(6.0)$ & $0.437 * *$ & $0.91(0.84,0.99)^{\star *}$ \\
\hline Anxiety (range = 0-24) & & $8.3(5.3)$ & $0.406^{* *}$ & $0.96(0.88,1.04)^{* *}$ \\
\hline Spirituality (range $=0-100$ ) & & $38.5(28.5)$ & $0.074^{* *}$ & $2.41(1.65 .3 .18)^{\star *}$ \\
\hline
\end{tabular}

Table 2 Correlations of spirituality and mental health conditions in healthcare professionals $(n=3006)$

\begin{tabular}{|c|c|c|c|c|}
\hline \multirow[b]{2}{*}{ Variable } & \multicolumn{2}{|c|}{ Depression (PHQ) } & \multicolumn{2}{|c|}{ Anxiety (GAD) } \\
\hline & Mean (s.d.)/ $/ r^{\mathrm{a}}$ & $B(95 \% \mathrm{Cl})^{\mathrm{b}}$ & Mean (s.d.)/ $/ r^{a}$ & $B(95 \% \mathrm{Cl})^{\mathrm{b}}$ \\
\hline \multicolumn{5}{|l|}{ Religious affiliation } \\
\hline No & $10.5(6.0)$ & $0.21(-0.12,0.55)$ & $8.2(5.3)$ & $0.08(-0.21,0.38)$ \\
\hline Christian & $11.9(5.4)$ & & $8.8(5.5)$ & \\
\hline Buddhist/Taoist & $10.9(6.6)$ & & $8.6(5.7)$ & \\
\hline Islam & $11.5(5.6)$ & & $8.7(4.6)$ & \\
\hline Spirituality $^{\mathrm{C}}$ (range = 0-100) & $0.043^{*}$ & $0.74(0.24,1.24)^{\star *}$ & 0.034 & $0.65(0.21,1.09)^{\star \star}$ \\
\hline
\end{tabular}

held a bachelor's degree in their field (in China, a bachelor's degree is sufficient to practice medicine). The average age of participants was 35.4 years (s.d. $=8.1$ ), ranging from 20 to 70 years. The average length of practice was 11.6 years (ranging from 2 to 50 years). Most participants (89.2\%) indicated no religious affiliation; among those having a religion, Islam was the most common religious affiliation. Spirituality scores ranged from 0 to 100 , with an average of 38.5 (s.d. $=28.5$ ) and a median score of 40 . Christians reported the highest score on spirituality $(72$, s.d. $=27)$, Buddhist/ Taoists reported similar scores to those of Muslims (58, s.d. $=27$ v. 59 , s.d. $=25$, respectively), and those who indicated no religion reported the lowest scores $(35$, s.d. $=27)$.

Bivariate analyses are presented in Table 1. Unmarried participants scored higher on the MISS-HP compared with those who were married, divorced or widowed $(P<0.01)$. Older participants and those who had spent longer in practice scored lower on moral injury symptoms. Both depressive (PHQ-9) and anxiety (GAD-7) symptoms were strongly and positively related to MISSHP scores $(P<0.01)$. Spirituality was related to higher MISS-HP scores. No significant difference in moral injury symptoms was found between those having a religious affiliation and those without an affiliation. The associations between spirituality and moral injury persisted in the multivariate analysis after controlling for sociodemographic variables.

As indicated in Table 2, no significant difference was found in PHQ-9 or GAD-7 scores among groups based on religious affiliation. Multivariate analyses revealed that spirituality was positively correlated with depressive symptoms $(\beta=0.74, P<0.01)$ and with 
Table 3 Model examining the mediating effect of moral injury on the relationship between spirituality and depression/anxiety

Bias-corrected $95 \% \mathrm{Cl}$

\begin{tabular}{|c|c|c|c|c|c|}
\hline Effect & $B$ & s.e. & $P$-value & Lower & Upper \\
\hline \multicolumn{6}{|c|}{ Depressive symptoms } \\
\hline Total effect & 0.76 & 0.18 & $<0.001$ & 0.42 & 1.11 \\
\hline Indirect effects & 0.46 & 0.08 & $<0.001$ & 0.30 & 0.63 \\
\hline Direct effects & 0.30 & 0.16 & 0.064 & -0.02 & 0.62 \\
\hline \multicolumn{6}{|l|}{ Anxiety symptoms } \\
\hline Total effect & 0.65 & 0.16 & $<0.001$ & 0.34 & 0.95 \\
\hline Indirect effects & 0.38 & 0.07 & $<0.001$ & 0.24 & 0.52 \\
\hline Direct effects & 0.27 & 0.14 & 0.067 & -0.02 & 0.55 \\
\hline
\end{tabular}

anxiety symptoms $(\beta=0.65, P<0.01)$. Results of the mediation analysis are presented in Table 3, controlling for age, gender, education, marital status and work area. The mediation effect of moral injury on the relationship between spirituality and both depression and anxiety was significant $(P<0.001)$. Moral injury explained $60 \%$ $(0.46 / 0.76)$ of the total association between spirituality and depression and $58 \%(0.38 / 0.65)$ of the association between spirituality and anxiety. As demonstrated in Table 4, moral injury did not moderate the association between spirituality and either depression or anxiety (interaction for depression, $\beta=-0.01, P=0.55$; interaction for anxiety, $\beta=-0.01, P=0.26$ ) (model 3 ).

\section{Discussion}

To our knowledge, this is the first study to explore the relationship between spirituality, moral injury and mental health (depression/ anxiety) in a large sample of healthcare professionals during the COVID-19 pandemic in mainland China. We found that spirituality was positively associated with moral injury, depressive symptoms and anxiety symptoms. These findings are not consistent with previous reports indicating that spirituality was inversely associated with moral injury in US veterans and healthcare professionals living in a religious society. ${ }^{18,19}$ These conflicting results may be due to the measure of moral injury used in the present study, which assesses psychological symptoms and struggles with beliefs; these may be more common among those with religious faith, especially in a highly secular country. ${ }^{23}$ Several studies conducted in mainland China have reported a positive relationship between spirituality and mental health problems. ${ }^{34,35}$ Previous studies have also found that Chinese health professionals with a Buddhist/Taoist religious affiliation experienced a higher risk of moral injury than those with no religious preference. ${ }^{36}$ One possible explanation is that having a Buddhist/Taoist religious affiliation may indicate higher moral standards that need to be lived up to, making these health professionals particularly vulnerable to moral injury. Chinese health professionals who are religious may feel abandoned or punished by God when experiencing difficult life situations, resulting in a higher degree of moral distress. ${ }^{37}$ At least one study has reported that religious and moral issues among minority Muslims in Germany generated stress among women, leading to a higher level of mental distress. ${ }^{38}$ More religious healthcare professionals may be driven by higher values and morals that make them feel more responsible to 'do something' to help others. When faced with system-related problems that prevent them from doing this, they may feel helpless and therefore develop symptoms of anxiety or depression.

Multivariate analyses in the current study found that moral injury was positively associated with both depression and anxiety symptoms. Moral injury has been consistently shown to coexist with adverse mental health outcomes including suicide, depression, PTSD, and substance misuse in military populations. ${ }^{39,40}$ Although the present study used a cross-sectional design that prevented causal inferences, spiritual-based interventions directed at moral injury have effectively reduced PTSD and other negative emotions among military personnel. ${ }^{22,23}$ Likewise, Mantri and colleagues found in a sample of US healthcare professionals that moral injury was associated with significantly higher depression and anxiety, ${ }^{18}$ as in the present study.

We considered two pathways by which moral injury might affect the relationship between spirituality and depression/anxiety: mediation or moderation. Results from the mediation model indicated that moral injury explained a majority of the variance in the relationship between spirituality and both depression and anxiety. The findings suggest that more spiritual Chinese health professionals may have been more sensitive emotionally to moral concerns over transgressing moral boundaries while carrying out their duties during the COVID-19 pandemic, where decisions might have involved who to treat and who not to treat, given the limited resources available. Finally, we did not find that moral injury moderated the relationship between spirituality and depression/anxiety, indicating that the relationship between spirituality and depression/anxiety was positive regardless of the level of moral injury.

Although religion (as an important component of spirituality) has been shown to increase levels of hope in US veterans and active-duty military, ${ }^{41}$ this dynamic may be difficult to demonstrate

\begin{tabular}{|c|c|c|c|c|c|c|}
\hline \multirow[b]{2}{*}{ Variables } & \multicolumn{2}{|c|}{ Model 1} & \multicolumn{2}{|c|}{ Model 2} & \multicolumn{2}{|c|}{ Model 3} \\
\hline & $P$-value & $B(95 \% \mathrm{Cl})$ & $P$-value & $B(95 \% \mathrm{Cl})$ & $P$-value & $B(95 \% \mathrm{Cl})$ \\
\hline \multicolumn{7}{|l|}{ Depressive symptoms } \\
\hline Constant & $<0.001$ & $11.25(10.0,12.4)$ & 0.020 & $1.58(0.25,2.91)$ & 0.425 & $0.97(-1.42,3.37)$ \\
\hline Spirituality ${ }^{a}$ & 0.001 & $0.85(0.33,1.37)$ & 0.180 & $0.29(-0.13,0.73)$ & 0.337 & $0.73(-0.76,2.22)$ \\
\hline MISS-HP & - & - & $<0.001$ & $0.20(0.18,0.22)$ & $<0.001$ & $0.21(0.17,0.22)$ \\
\hline Spirituality $\times$ MISS-HP & - & - & - & - & 0.552 & $-0.01(-0.04,0.02)$ \\
\hline Model $R^{2} / \Delta R^{2}$ & - & 0.010/- & - & $0.193 / 0.184^{* *}$ & - & $0.193 / 0.000$ \\
\hline \multicolumn{7}{|l|}{ Anxiety symptoms } \\
\hline Constant & $<0.001$ & $9.89(9.04,10.75)$ & 0.158 & $0.85(-0.33,2.05)$ & 0.877 & $-0.17(-2.32,1.98)$ \\
\hline Spirituality $^{a}$ & 0.001 & $0.69(0.26,1.11)$ & 0.238 & $0.23(-0.15,0.62)$ & 0.075 & $0.97(-0.36,2.23)$ \\
\hline MISS-HP & - & - & $<0.001$ & $0.16(0.15,0.18)$ & $<0.001$ & $0.19(0.14,0.23)$ \\
\hline Spirituality $\times$ MISS-HP & - & - & - & - & 0.259 & $-0.01(-0.04,-0.01)$ \\
\hline Model $R^{2} / \Delta R^{2}$ & - & $0.010 /-$ & - & $0.167 / 0.166 * *$ & - & $0.168 / 0.001$ \\
\hline
\end{tabular}

Model 1, independent variables include demographical variables; Model 2, Model 1 + MISS-HP; Model 3, model 2 + interaction; MISS-HP, Moral Injury Symptoms Scale-Health Professional. a. Logarithm-transformed score to fit normal distribution. $\star * R^{2}$ change test $P<0.01$. 
in a largely secular population of Chinese healthcare professionals owing to differences in the cultural background. Repeated moral injury experience over time may also cause Chinese healthcare professionals to become more resistant to morally injurious events, as suggested by the finding that healthcare professionals who were older or had been in practice longer reported fewer moral injuries.

The findings here provide preliminary evidence to support addressing spiritual issues when treating Chinese healthcare professionals struggling with moral injury arising during the COVID-19 pandemic. $^{21}$ Doing so may help to improve depressive and anxiety symptoms in these healthcare providers during the pandemic and other major public health events associated with potentially morally challenging decisions, which Chinese healthcare professionals will inevitably face in the future.

\section{Study limitations}

Several limitations affect the interpretation and generalisability of the findings reported here. First, the non-random sampling method used to select participants may affect the ability to generalise results to healthcare professionals across China. Second, the cross-sectional design prevents causal inferences being drawn regarding the relationships among spirituality, moral injury and depression/anxiety found here. Finally, as all measures were selfrated, the accuracy of responses cannot be guaranteed, although previously established reliable and valid measures were used in the assessment of moral injury, depression and anxiety symptoms.

\section{Implications}

Spirituality was positively correlated with moral injury and poor mental health in this sample of Chinese healthcare professionals during the height of the COVID-19 pandemic. Moral injury mediated a significant proportion of the associations between spirituality and both depression and anxiety, suggesting that concern over transgressing moral values during the pandemic may have been a driving force in generating depression and anxiety symptoms among these Chinese healthcare professionals. Although future longitudinal studies are needed to determine the causal nature of these relationships, the present findings provide preliminary evidence that may help to justify the addressing of spiritual issues when treating Chinese healthcare professionals with symptoms of depression and anxiety during the COVID-19 pandemic.

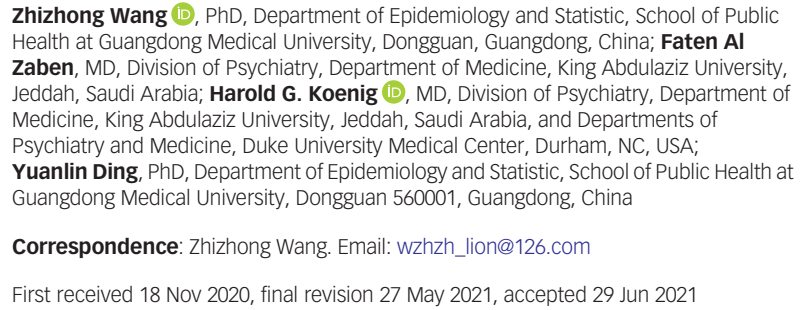

\section{Data availability}

All data generated or analysed during this study are included in this published article. Additional requests can be made to the corresponding author at wzhzh_lion@126.com.

\section{Acknowledgements}

We acknowledge Dr Z. T. Xue for her assistance in preparing the questionnaire, and Drs M. Sui, J. Wen and $\mathrm{Y}$. Tong for help with data collection.

\section{Authors' contributions}

Z.Z.W. and H.G.K. were responsible for the study concept and design; Z.Z.W. was responsible for acquisition of subjects and data collection; Z.Z.W., F.A.Z. and H.G.K. performed analysis and interpretation of the data; Z.Z.W., H.G.K. and Y.L.D. prepared the manuscript; and Z.Z.W. F.A.Z., H.G.K. and Y.L.D. revised the manuscript for critical intellectual content.

\section{Funding}

The China Medical Board (CMB16-254) and the Discipline Construction Project of Guangdong Medical University (4SG21264P) supported this study.

\section{Declaration of interest}

None.

\section{References}

1 Williamson V, Murphy D, Greenberg N. COVID-19 and experiences of moral injury in front-line key workers. Occup Med 2020; 70(5): 317-9.

2 Horsch A, Lalor J, Downe S. Moral and mental health challenges faced by maternity staff during the COVID-19 pandemic. Psychol Trauma 2020; 12(S1): S141-2.

3 Litz BT, Stein N, Delaney E, Lebowitz L, Nash WP, Silva C, et al. Moral injury and moral repair in war veterans: a preliminary model and intervention strategy. Clin Psychol Rev 2009; 29(8): 695-706.

4 Nieuwsma JA, Walser RD, Farnsworth JK, Drescher KD, Meador KG, Nash WP. Possibilities within acceptance and commitment therapy for approaching moral injury. Curr Psychiatry Rev 2015; 11: 193-206.

5 Bryan AO, Bryan CJ, Morrow CE, Etienne N, Ray-Sannerud B. Moral injury, suicidal ideation, and suicide attempts in a military sample. Traumatology 2014; 20(3): 154-64.

6 Battles AR, Bravo AJ, Kelley ML, Whit TD, Braitman AL, Hamrick HC. Moral injury and PTSD as mediators of the associations between morally injurious experiences and mental health and substance use. Traumatology 2018; 24(4): 246-54.

7 Ames D, Erickson Z, Youssef NA, Arnold I, Adamson CS, Sones AC, et al. Moral injury, religiosity, and suicide risk in US veterans and active duty military with PTSD symptoms. Mil Med 2019; 184(3-4): e271-8.

8 Ford EW. Stress, burnout, and moral injury: the state of the healthcare workforce. J Healthc Manag 2019; 64(3): 125-7.

9 Frezza E. Moral injury: the pandemic for physicians. Tex Med 2019; 115(3): 4-6.

10 BBC News. Coronavirus: Why Healthcare Workers are at Risk of Moral Injury. BBC, 2020 (https://www.bbc.com/news/world-us-canada-52144859 [cited 5 May 2021]).

11 Tucker JD, Cheng Y, Wong B, Gong N, Nie JB, Zhu W, et al. Patient-physician mistrust and violence against physicians in Guangdong Province, China: a qualitative study. BMJ Open 2015; 5(10): e008221.

12 Lancet T. Violence against doctors: why China? Why now? What next? Lancet 2014; 383(9922): 1013.

13 Pan $Y$, Yang X, He JP, Gu YH, Zhan XL, Gu HF, et al. To be or not to be a doctor, that is the question: a review of serious incidents of violence against doctors in China from 2003-2013. J Public Health 2015; 23(2): 111-6.

14 Murray E, Krahé C, Goodsman D. Are medical students in prehospital care at risk of moral injury? Emerg Med J 2018; 35(10): 590-94.

15 Medical Dictionary. Spirituality. Farlex and Partners, 2009 (https://medicaldictionary.thefreedictionary.com/spirituality [cited 24 Mar 2021]).

16 Smith-MacDonald LA, Morin JS, Brémault-Phillips S. Spiritual dimensions of moral injury: contributions of mental health chaplains in the Canadian armed forces. Front Psychiatry 2018; 9: e592.

17 Koenig HG, Youssef NA, Ames D, Oliver JP, Teng EJ, Haynes K, et al. Moral injury and religiosity in US veterans with posttraumatic stress disorder symptoms. J Nerv Ment Dis 2018; 206(5): 325-31.

18 Mantri S, Lawson JM, Wang ZZ, Koenig HG. Prevalence and predictors of moral injury in healthcare professionals. J Nerv Ment Dis 2021; 209(3): 174-80.

19 Youssef NA, Boswell E, Fiedler S, Jump R, Lee E, Yassa M, et al. Moral injury, posttraumatic stress disorder, and religious involvement among US veterans. Ann Clin Psychiatry 2018; 30(2): 113-21.

20 Worthington EL, Langberg D. Religious considerations and self-forgiveness in treating complex trauma and moral injury in present and former soldiers. J Psychol Theol 2012; 40: 274-88.

21 Koenig HG, Ames D, Nash W, Büssing A. Screening for and treatment of moral injury in veterans/active duty military with PTSD. Front Psychiatry 2019; 10: e596.

22 Pearce M, Haynes K, Rivera NR, Koenig HG. Spiritually integrated cognitive processing therapy: a new treatment for post-traumatic stress disorder that targets moral injury. Glob Adv Health Med 2018; 7: 1-7.

23 Harris Jl, Usset T, Voecks C, Thuras P, Currier J, Erbes C. Spiritually integrated care for PTSD: a randomized controlled trial of "building spiritual strength". Psychiatry Res 2018; 267: 420-8. 
24 Wang ZZ, Koenig HG, Tong Y, Wen J, Sui M, Liu H, et al. Psychometric properties of the Moral Injury Symptoms Scale among Chinese health professionals during the COVID-19 pandemic. BMC Psychiatry 2020; 20(1): e556.

25 Mantri S, Lawson JM, Wang ZZ, Koenig HG. Identifying moral injury in healthcare professionals: the moral injury symptoms scale-HP. J Relig Health 2020; 59: 2323-40.

26 Koenig HG, Ames D, Youssef NA, Oliver JP, Volk F, Teng EJ, et al. Screening for moral injury: the moral injury symptom scale-military version short form. Mil Med 2018; 183(11-12): 659-65.

$27 \mathrm{Cha}$ ES, Kim KH, Erlen JA. Translation of scales in cross-cultural research: issues and techniques. J Adv Nurs 2007; 58(4): 386-95.

28 Kroenke K, Spitzer RL, Williams JB. The PHQ-9: validity of a brief depression severity measure. J Gen Intern Med 2001; 16(9): 606-13.

29 Spitzer RL, Kroenke K, Williams JB, Lowe B. A brief measure for assessing generalized anxiety disorder: GAD-7. Arch Intern Med 2006; 166(10): 1092-97.

30 Zhang YL, Liang W, Chen ZM, Zhang HM, Zhang JH, Weng XQ, et al. Validity and reliability of Patient Health Questionnaire-9 and Patient Health Questionnaire-2 to screen for depression among college students in China. Asia-Pacific Psychiatry 2013; 5(4): 268-75.

31 He XY, Li CB, Qian J, Cui HS, Wu WY. Reliability and validity of a generalized anxiety scale in general hospital outpatients. Shanghai Arch Psychiatry 2010; 22(4): $200-3$.

32 Payne IR, Bergin $A E$, Bielema KA, Jenkins $P H$. Review of religion and mental health: prevention and the enhancement of psychosocial functioning. Prev Hum Serv 1991; 9(2): 11-40.

33 Hayes A. Introduction to mediation, moderation, and conditional process anaIysis. J Educ Meas 2013; 51: 335-7.
34 Wang ZZ, Koenig HG, Zhang YH, Ma WR, Huang YQ. Religious involvement and mental disorders in Mainland China. PLOS One 2015; 10(6): e0128800.

35 McClintock $\mathrm{CH}$, Lau $\mathrm{E}$, Miller L. Phenotypic dimensions of spirituality: implications for mental health in China, India, and the United States. Front Psychol 2016; 7: e1600.

36 Wang ZZ, Koenig HG, Tong Y, Wen J, Sui M, Liu H, et al. Moral injury of healthcare worker under the COVID-19 pandemic. Psychol. Trauma 2021. Available from: https://doi.org/10.1037/tra0001026.

37 Braam AW, Schrier AC, Tuinebreijer WC, Beekman ATF, Dekker JJM, de Wit MA. Religious coping and depression in multicultural Amsterdam: a comparison between native Dutch citizens and Turkish, Moroccan and Surinamese/ Antillean migrants. J Affect Disord 2010; 125: 269-78.

38 Irfaeya M, Maxwell AE, Krämer A. Assessing psychological stress among arab migrant women in the City of Cologne/Germany using the community oriented primary care (COPC) approach. J Immigr Minor Health 2008; 10: 337-44.

39 Battles AR, Bravo AJ, Kelley ML, Whit TD, Braitman AL, Hamrick HC. Moral injury and PTSD as mediators of the associations between morally injurious experiences and mental health and substance use. Traumatology 2018; 24: 246-54.

40 Bryan AO, Bryan CJ, Morrow CE, Etienne N, Ray-Sannerud B. Moral injury, suicidal ideation, and suicide attempts in a military sample. Traumatology 2014; 20: $154-64$.

41 Koenig HG, Youssef NA, Smothers Z, Oliver JP, Boucher NA, Ames D, et al. Hope, religiosity, and mental health in U.S. veterans and active duty military with PTSD symptoms. Mil Med 2020; 185(12): 97-104.

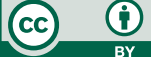

